\title{
O Uso de Informações por Analistas de Investimento na Avaliação de Empresas: à Procura de Padrões
}

\author{
Luiz Henrique Boff \\ Jairo Laser Procianoy \\ Norberto Hoppen
}

\section{RESUMO}

A informação é hoje um dos principais recursos dos trabalhadores do conhecimento na resolução de problemas, mas pouco se sabe sobre a natureza de sua utilização. $\mathrm{O}$ analista de investimentos é um trabalhador de conhecimento que utiliza e produz informações com o objetivo de avaliar empresas e setores produtivos para identificar boas oportunidades de investimento. No contexto do mercado de capitais, a literatura tem enfatizado a importância em utilizar informações disponíveis para identificar oportunidades, recomendar adequadamente investimentos e, com isso, apresentar bons retornos. É um enfoque que não evidencia todo o processo pelo qual as informações são adquiridas e, depois, processadas, interpretadas e integradas, num esforço para identificar um bom investimento. Há, portanto, necessidade de investigação para conhecer esse processo. O objetivo deste trabalho é mapear, através de um estudo de campo de natureza qualitativa, o processo de uso da informação por analistas de investimentos e verificar se há diversidade ou padronização nos seus procedimentos e decisões. O estudo acompanhou a atividade de 27 analistas de nível sênior durante a avaliação de uma empresa. São apresentados comentários sobre a aplicação dos resultados e a contribuição do estudo para o trabalho do analista de investimentos.

Palavras-chave: gestão da informação; processo cognitivo; análise de investimentos.

\begin{abstract}
Information is one of the knowledge workers' main resources in problem solving. However, the nature of information use is not well known in this environment. Securities analysts are knowledge workers that use and produce information to evaluate companies and industry sectors to identify good investment opportunities. Capital market literature has been emphasizing the importance in using available information to identify opportunities, to give appropriate investment recommendations and then to get return of investment. It is an approach that does not make evident the information process - acquisition, processing, interpretation, and integration - to identify a good investment. There is a gap that suggests an investigation to know that process. The purpose of this article is to perform a qualitative exploratory research to map the information use process by securities analysts and to verify whether there is diversity or standardization in their procedures and decisions. The study followed the activities of 27 senior securities analyst during a company evaluation. The results and comments are presented to support the contributions of the study and their implications for the securities analyst work.
\end{abstract}

Key words: information management; cognitive process; securities analysis. 


\section{INTRODUÇÃO}

$\mathrm{O}$ analista de investimentos ${ }^{(1)}$, assim como outros profissionais ligados à prestação de serviços, possui diversas habilidades voltadas para o uso e a produção de informações, com o objetivo principal de fazer recomendações acerca de uma empresa ou setor avaliado. Como sua principal atividade busca identificar boas oportunidades de investimento, o analista trabalha como um intermediário de informações, conciliando os interesses dos ofertantes e dos tomadores de recursos. Embora seja um trabalho cooperativo, que depende de uma rede de relações pessoais e institucionais, a análise é, geralmente, realizada de forma individual.

$\mathrm{O}$ analista de investimentos insere-se num contexto de mudanças, principalmente porque o mercado de capitais no Brasil tem alterado seu perfil nas últimas décadas. A diminuição do ambiente especulativo e o ingresso de investimentos estrangeiros no país exigiram melhor estrutura do setor e a necessidade de mais profissionalismo na análise de investimentos.

No contexto do mercado de capitais, o ambiente de informações é complexo e dinâmico. A informação desempenha papel fundamental para orientar as decisões e ações dos analistas. O mercado é reflexo das expectativas dos investidores. Os recursos são aplicados naquelas ações de empresas que indicam desempenho futuro satisfatório, ou seja, tenham possibilidade de gerar ganhos de capital ou de dividendos para seus investidores. Para prever o desempenho das empresas, os analistas adquirem informações, fazem projeções e inferências para desenhar tendências futuras. Entretanto, há fatores limitadores na análise, como disponibilidade, atualidade, formato e integridade das informações. Embora devesse ser esta a regra básica de um mercado desenvolvido e eficiente, nem todos os analistas têm acesso às mesmas informações, ao mesmo tempo, da mesma maneira. Além disso, há diferentes interpretações individuais para as mesmas informações, produzindo resultados diferentes, como se detalha a seguir.

O trabalho clássico de Fama (1970) ilustra muito bem a dificuldade de determinar um bom investimento baseado no que ele chama de três formas de eficiência do mercado de capitais: fraca, semiforte e forte. Na forma fraca, nenhum investidor obterá ganhos excessivos baseado em informações do passado sobre preços e regras conhecidas do mercado. Na forma semiforte, não há lucro extraordinário baseado na informação pública disponível, como demonstrações financeiras divulgadas pela empresa e dados históricos dos 
preços. A forma forte é, por definição, o mercado eficiente. Ou seja, ninguém pode ter retorno excessivo com base em toda a informação relevante, pública ou privada, pois ela é imediatamente incorporada ao valor do investimento, isso é, a informação é precificada.

Qual seria a forma do mercado? Sundali e Atkins (1994) identificaram que especialistas em análise de investimentos têm desempenho superior às médias do mercado. E outros estudos verificaram que insiders (quem obtêm informação privilegiada) obtiveram retornos anormais em operações no mercado de capitais (Dervin, 1992; Finnerty, 1976; Seyhun, 1986).

Existem algumas evidências de que o mercado norte-americano ainda não atingiu a forma semiforte. Bernard e Thomas (1990) comprovaram que o mercado não reage imediatamente aos anúncios de lucros das empresas. Outros trabalhos, ao contrário dos resultados obtidos por Sundali e Atkins, mostram que especialistas e investidores profissionais têm obtido desempenho inferior aos índices de mercado (Berkowitz et al., 1988; Brinson et al., 1986; Staël Von Holstein, 1972; Yates et al., 1991). Para o mercado brasileiro poucas pesquisas foram realizadas.

Os estudos mencionados mostram a importância do trabalho de análise de investimentos, mas o enfoque é sempre nos resultados alcançados. Não é evidenciado o processo pelo qual o analista adquire e interpreta informações para identificar um bom investimento antes do mercado. Ou seja, pode-se deslocar o eixo de análise das definições de Fama para o uso das informações disponíveis. Há, portanto, a necessidade de investigação para conhecer esse processo.

O objetivo deste trabalho é mapear o processo de uso da informação por analistas de investimentos para a precificação de ativos. Para isso, foram identificadas várias questões que são recorrentes para esses profissionais: Como são identificadas as empresas a serem analisadas? Quais as informações e fontes mais importantes e a frequiência de acesso a essas informações? Como é o processo entre a aquisição da informação e sua utilização? Como o analista decide quando tem informações suficientes para realizar seu trabalho? Como ele constrói a sua opinião a partir das informações analisadas? As atividades de análise seguem um padrão ou são diversificadas? Para responder a essas questões, foi realizado um estudo experimental de campo que acompanhou a atividade de analistas de investimentos sob a ótica do uso da informação.

Vários profissionais podem fazer uso dos resultados desta pesquisa, em termos de mapeamento de padrões do trabalho observado e de análise do limite desses padrões, como um marco no relacionamento e na estrutura de avaliação. Dentre eles, destacam-se profissionais com atividades no mercado de capitais, atuando no processo de compra e venda de ações; os profissionais que avaliam empresas, 
com ações negociadas em bolsa ou não; e os profissionais vinculados a projetos de investimento e decisão de alocação de capitais internos nas empresas.

O presente trabalho é apresentado da seguinte forma: a segunda seção descreve a metodologia da pesquisa realizada; na terceira seção são apresentados os resultados da primeira fase do estudo: o mapeamento do processo de análise; a quarta seção apresenta os resultados da segunda fase, que investiga o uso da informação por analistas durante a avaliação de uma empresa; a quinta seção comenta a aplicação dos resultados e faz considerações sobre a contribuição do estudo para o trabalho do analista de investimentos. Finalmente, as conclusões tratam das limitações da pesquisa e recomendações para a capacitação dos novos analistas de investimento.

\section{Descrição da Pesquisa com Analistas de Investimentos}

\section{Fases da Pesquisa}

Esta pesquisa é caracterizada como um estudo de campo de natureza qualitativa e foi realizada em duas fases distintas. A primeira foi um estudo exploratório das atividades dos analistas de investimento. A segunda consistiu na realização de um estudo quase-experimental (denominado "experimento") que representa o processo de análise de uma empresa.

O objetivo do estudo exploratório foi mapear o processo de análise de investimentos, ou seja, identificar as estratégias de análise, as informações adquiridas e respectivas fontes, técnicas e recursos de processamento utilizados e resultados produzidos. Nessa fase, foram entrevistados três analistas que atuam em corretoras de Porto Alegre e São Paulo e acompanhadas as avaliações de três empresas durante todo o processo: seleção da empresa, contatos e visitas, coleta de informações e documentos, pesquisas, tratamento das informações, discussões com outros analistas e elaboração do relatório de análise.

A segunda fase foi um experimento com 27 analistas de nível sênior. Cada um avaliou uma mesma empresa - uma franquia de serviços de reparação e manutenção de automóveis - e definiu sua recomendação sobre o investimento. Para realizar esse experimento, foram definidos e validados um cenário e uma tarefa de avaliação (ver procedimentos em Boff \& Hoppen, 2001), representando uma situação típica do processo de trabalho de análise de investimentos, de acordo com as características identificadas no estudo exploratório (primeira fase). Com isso, estabeleceu-se o mesmo estímulo para os participantes da pesquisa e criaramse condições adequadas para medir variáveis específicas do processo de trabalho. 
Optou-se por desenvolver o cenário com base em informações reais sobre a empresa escolhida. Os pesquisadores mantiveram contato com os administradores e funcionários da empresa e tiveram acesso às instalações, para conhecer os produtos, serviços, fluxos de trabalho, e às informações e documentos, como planos, demonstrativos financeiros, manuais e material promocional, entre outros. As informações selecionadas, extraídas de depoimentos e documentos, foram incorporadas ao cenário sem alteração de conteúdo, procurando representar as condições em que o analista de investimentos receberia as informações, se fizesse o contato diretamente com a empresa. A forma de apresentação foi adaptada, apenas quando necessário, para se adequar ao instrumento. Com base na situação real da empresa e na sua estratégia de expansão, foi criada uma oportunidade de investimento hipotética. Outra característica importante do cenário foi a escolha de uma empresa de um setor de atividade que não estivesse presente no mercado de capitais e com pouco tempo de operação, para evitar avaliações com conhecimento prévio $^{(2)}$ e potenciais riscos de vieses nos resultados (Boff \& Hoppen, 2001).

O cenário foi elaborado com três grupos de informações: básicas sobre a empresa (setor de atividade, histórico, processo de abertura no Brasil, produtos e serviços prestados etc.); sobre a tarefa a ser executada pelo analista (avaliação da empresa para captação de recursos no mercado); e adicionais sobre a empresa (demonstrações financeiras, contrato de franquia, investimentos realizados, características operacionais, estratégia de comunicação etc.).

Os analistas realizaram a tarefa individualmente, passando por quatro etapas iguais:

- Inicial. Recebe o cenário com as informações básicas sobre a empresa e a descrição da tarefa que deve ser realizada (avaliar a empresa); realiza uma análise preliminar da proposta de investimento e registra a sua opinião.

- Planejamento. Explicita a sua estratégia de análise, descrevendo o processo utilizado para identificar a situação, as informações necessárias, as formas de obtê-las e tratá-las.

Análise. Classifica as informações disponíveis na ordem em que deseja recebêlas para realizar a tarefa; recebe as informações, na seqüência definida; para cada informação, descreve verbalmente os seus procedimentos de análise, julga a informação recebida quanto ao seu grau de relevância e complexidade e define uma posição para o investimento; esse procedimento é repetido até o final das informações disponíveis.

- Final. Define a sua posição final sobre a oportunidade de investimento; discute o processo de análise e a representatividade do cenário. 
Embora o experimento reproduza todas as etapas da análise, o principal objetivo dessa seqüência não foi obter uma recomendação de investimento, mas captar a dinâmica do processo de aquisição e uso da informação, produção de resultados e compreensão do cenário.

\section{Descrição da Amostra}

A amostra da pesquisa foi retirada de um universo de analistas de investimento que atuam em corretoras, bancos e fundos de pensão em São Paulo e Rio de Janeiro. Os critérios para a escolha foram: nível profissional (especialista $\left.{ }^{(3)}\right)$, cargo (gerente ou analista sênior), tempo na atividade profissional (mínimo de cinco anos) e tipo de atividade (análise de empresas para realizar investimentos).

Os 27 analistas que realizaram o experimento se enquadraram nos critérios estabelecidos. Na época da pesquisa, em média, os participantes trabalhavam há 10 anos na área de análise, a maioria em bancos de investimentos (70\%). Todos eram graduados (41\% em Economia) e 85\% tinham título de pós-graduação (70\% em Administração, nas áreas de Finanças e Mercado de Capitais), sendo 55\% com especialização e $30 \%$ com Mestrado ou Doutorado. Todos os analistas foram considerados por seus colegas ou superiores como profissionais de ótimo desempenho. O perfil de especialista para a pesquisa foi considerado fundamental para evitar vieses de análises não fundamentadas ou inconsistentes.

A seguir, são apresentados os resultados das duas fases da pesquisa. Pela natureza qualitativa do estudo e pela característica de mapeamento do processo de análise, os resultados são apresentados de forma descritiva e sintetizados em quadros e tabelas.

\section{Mapeamento do Processo de Análise de Investimentos}

A primeira fase da pesquisa evidenciou, de forma geral, o processo de análise de investimentos. Essa atividade obedece a um conjunto diversificado de ações, pois a análise inicial não segue, necessariamente, uma rotina estruturada. Por outro lado, foi possível identificar um caráter cíclico nas ações dos analistas que aponta para alguma padronização.

\section{A Diversidade da Análise}

A primeira ação, que dá início ao processo, é a identificação de uma oportunidade de investimento. Isso pode ocorrer de diversas maneiras: a área de administração de fundos do banco ou um investidor solicita uma avaliação, o analista identifica uma oportunidade a partir de um fato econômico ou político, o preço aparentemente 
atrativo das ações de uma empresa ou um setor em crescimento etc. Essa é uma característica marcante do trabalho de análise de investimentos. A origem da análise pode ser reativa (como solicitações de investidores) ou pró-ativa (fazer associações e avaliar os impactos causados por fatos relevantes).

A segunda ação é o planejamento da análise. $\mathrm{O}$ analista confronta a situação identificada com o seu conhecimento e experiência, para decidir que informações são necessárias. Os procedimentos variam muito, pois dependem do estilo do analista, do seu acesso às fontes, da complexidade das informações disponíveis e da tarefa a ser executada.

A opção por obter informações no início do processo evidencia a necessidade de buscar referências externas para adquirir maior conhecimento para a análise. Esse procedimento tem sido comprovado por várias pesquisas (ver, por exemplo: Choo \& Auster, 1993; Dervin, 1992; Newell \& Simon, 1972; Taylor, 1986); ele é determinado por fatores cognitivos, embora existam também componentes afetivos e situacionais envolvidos.

Obtidas as informações, o analista deve então interpretá-las. Essa atividade também está relacionada com o estilo do analista e com o grau de complexidade e relevância da informação. O estilo determina a forma como são interpretadas as informações. A complexidade e relevância dependem de como cada analista as percebe.

Depois de interpretadas, as informações são utilizadas para a atividade principal do analista: avaliar a empresa. Essa avaliação não acontece num momento específico, mas durante todo o processo. As atividades ao longo do processo contribuem para confirmar ou modificar sua opinião inicial e diminuir o grau de incerteza de sua decisão.

A fase final do processo é a decisão do analista sobre o investimento. Normalmente, essa decisão é apresentada na forma de um relatório. Nele, o analista propõe uma posição sobre o investimento e justifica a decisão, com argumentos, números, estimativas, comparações etc.

\section{Caráter Cíclico do Processo de Análise de Investimentos}

Depois de interpretar as informações e montar um quadro de referência do que foi analisado, é provável que existam lacunas a serem preenchidas e dúvidas sobre informações que não foram compreendidas. Nesse caso, uma segunda coleta de informações se faz necessária. Esse ciclo pode repetir-se várias vezes, de acordo com o estilo e o interesse do analista e também o objetivo e a importância da análise. 
O analista, agente principal do processo, realiza um conjunto de ações durante a avaliação - busca, seleção, processamento, interpretação e comparação de informações - para gerar o produto de seu trabalho. A Figura 1 apresenta a sequiência de ações típicas que representa o mapeamento do processo de análise de investimentos realizado neste estudo. As ações descritas podem ser repetidas várias vezes, até que o analista tome a decisão sobre o investimento.

\section{Figura 1: Mapa do Processo de Análise de Investimentos}

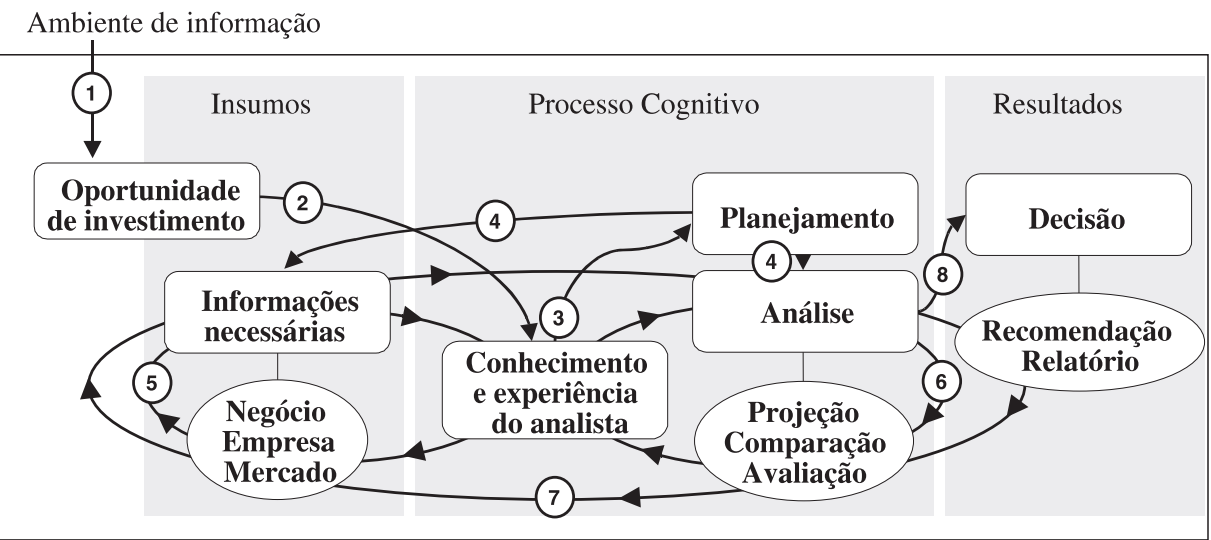

Legenda (ações do analista):

1 Identifica uma oportunidade de investimento no mercado

2 Confronta a situação com o seu conhecimento e experiência

3 Planeja a análise identificando as informações que possui e quais são necessárias

4 Inicia a análise com informações e parâmetros internos ou busca informações externas

5 Seleciona e interpreta as informações (sobre o negócio, a empresa e o mercado)

6 Compara as informações e utiliza-as para fazer projeções e avaliar a empresa

7 Busca novas informações e continua a análise

8 Toma a decisão e elabora um relatório de recomendação sobre o investimento

A diversidade e o caráter cíclico não são excludentes. Entretanto pode-se dizer que a diversidade é baseada nas diferentes características de cada profissional. Já os ciclos tendem à padronização, uma seqüência de ações que ocorre independentemente do perfil do analista.

\section{ANÁlise do EXPERIMENTO}

Os resultados desta fase são apresentados de acordo com a sequiência das etapas definidas no cenário (item Fases da Pesquisa). O estudo explorou o processo de análise a partir: (a) da avaliação das informações iniciais do cenário; 
(b) do planejamento - escolha das informações necessárias para avaliar a empresa e a definição de uma estratégia de análise; (c) da análise das informações adicionais sobre a empresa; e (d) da avaliação final e decisão sobre o investimento.

\section{Avaliação das Informações Iniciais}

Nesta etapa, foi possível identificar claramente a dificuldade de os analistas descreverem uma opinião sobre a empresa e definir uma proposta para o investimento. Identificaram-se dois grupos: um formado por 15 analistas $(55,6 \%)$, que não apresentaram proposta de investimento, e outro de 12 analistas $(44,4 \%)$, que tomaram a decisão inicial de investir na empresa. Nenhum analista optou por não realizar o investimento.

Todos os analistas que não apresentaram proposta alegaram que as informações fornecidas eram insuficientes. Mencionaram informações específicas - que não tinham sido fornecidas até aquele momento - como necessárias para a definir a proposta. Embora essa tarefa não tenha sido solicitada na avaliação inicial das informações, e sim numa etapa posterior (Informações necessárias para avaliar a empresa), é um comportamento compatível com o que foi apresentado na ação 3 da Figura 1: planejar a análise.

Com relação ao cenário, as informações iniciais eram deliberadamente insuficientes para se identificar o grau de conhecimento dos analistas em relação à empresa e ao negócio. A decisão em si não tem valor relevante para este estudo, mas sim os critérios que foram considerados para fazer a proposta. Por isso, identificou-se a associação de informações do cenário a parâmetros definidos pelos analistas. Esses parâmetros são informações internalizadas e consideradas válidas por quem as utiliza. Por exemplo, um parâmetro registrado por 5 analistas $(18,5 \%)$ foi a perspectiva de crescimento do setor automotivo no Brasil. A informação do cenário faturamento médio por loja no exterior serviu como referência, mas o que orientou a proposta (tamanho do mercado no Brasil, percentual de renda líquida e taxa de desconto) foram os parâmetros escolhidos pelos analistas. Outras evidências identificadas nos comentários sinalizam o esforço para estabelecer um grau de entendimento do cenário e preencher lacunas de informação: definir condições para realizar o investimento e entrar no negócio, confirmar os significados das informações fornecidas e fazer suposições.

A análise desta etapa identificou como os analistas interpretaram as informações externas e utilizaram suas informações internas para realizar a tarefa solicitada. A falta de informações externas nesta etapa preliminar dificulta a avaliação e faz 
com que os analistas acionem suas referências internas para estabelecer relações e procurar o significado do que é analisado.

\section{Planejamento para Avaliar a Empresa}

Após identificarem a oportunidade de investimento, receberem as informações iniciais e apresentarem uma proposta preliminar, os participantes planejaram a sua estratégia de análise. A primeira parte foi a identificação das informações necessárias para avaliar a empresa.

\section{Definição das Informações Necessárias}

A análise desta etapa mostra uma diversidade de informações identificadas como necessárias. Os participantes citaram 169 informações (consideradas apenas aquelas com freqüência igual ou superior a cinco), classificadas em 23 diferentes grupos, como mostra o Quadro 1.

\section{Quadro 1: Grupos de Informações Necessárias indicadas pelos Participantes}

\begin{tabular}{|l|l|l|}
\hline Ameaças & Estrutura da empresa & Margens \\
Análise de investimentos & Estrutura societária & Marketing \\
Aspectos legais & Informações sobre a economia* & Pesquisa \\
Business plan & Informações sobre a empresa* & Produtos e serviços \\
Casos & Informações sobre o mercado* & Projeções \\
Cenários & Informações sobre o negócio* & Rentabilidade \\
Comparações & Informações sobre o setor* & Veículos \\
Demonstrações financeiras & Informações sobre franquia & \\
\hline
\end{tabular}

* Informações mais citadas.

Para verificar o grau de relacionamento entre esses grupos, as informações indicadas pelos participantes foram cruzadas (ocorrências das informações nos mesmos depoimentos) e calcularam-se os respectivos índices de correlação (Spearman). A Figura 2 mostra o resultado das correlações significativas. 


\section{Figura 2: Relacionamento entre os Grupos de Informações Necessárias}

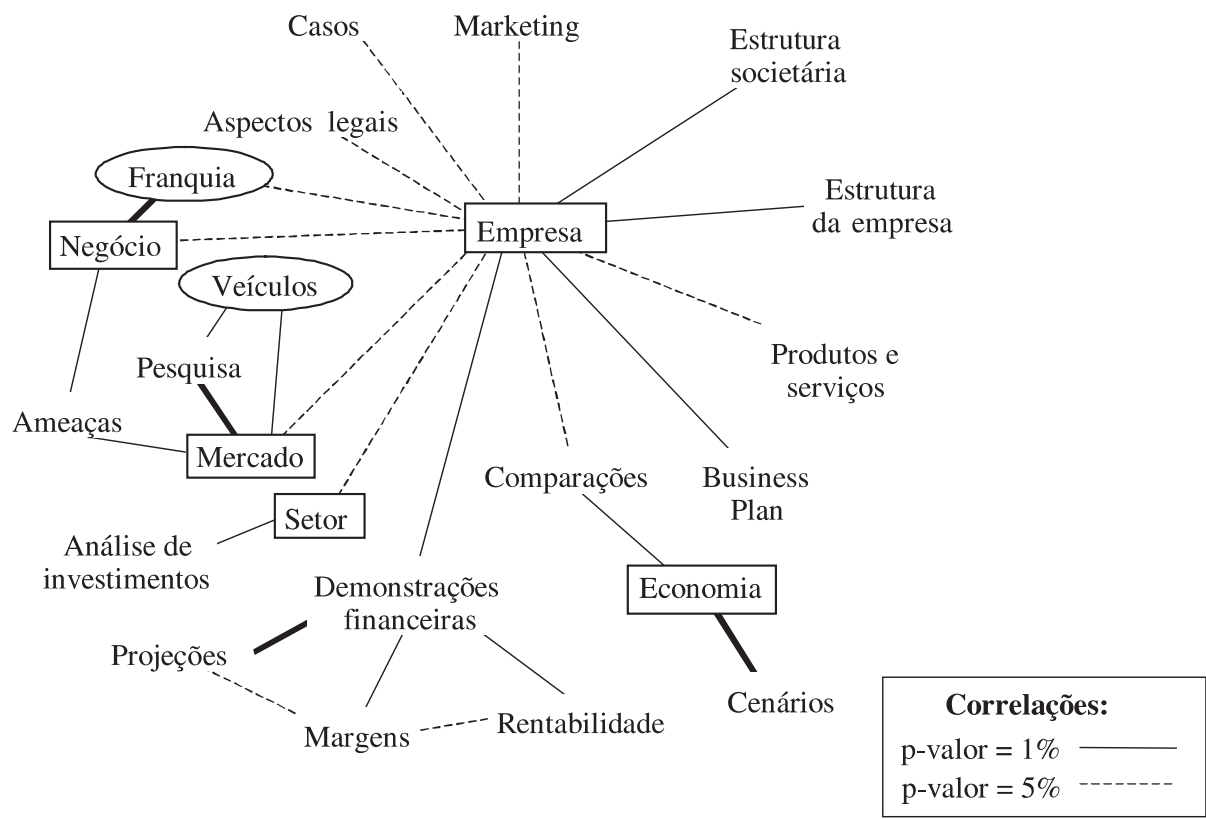

Os relacionamentos com maior correlação foram os seguintes (linhas mais grossas):

. Franquia e negócio $(\mathrm{rs}=0,82)$. Conhecer o negócio de franquia no ramo de reparação de automóveis.

. Economia e cenários $(r s=0,79)$. Considerar a influência da economia sobre a empresa, em diferentes cenários.

. Pesquisa e mercado $(\mathrm{rs}=0,73)$. Conhecer o potencial de mercado para o tipo de negócio.

. Demonstrações financeiras e projeções ( $r s=0,69)$. Avaliar o desempenho financeiro da empresa e estimar o retorno do investimento.

A Figura 2 também mostra uma forte e concentrada associação entre as informações financeiras e uma dispersão de informações não financeiras. Entretanto o grupo de informações sobre a empresa aparece como ponto central em relação aos outros grupos.

Outro ponto de destaque é que apenas dois grupos são temas específicos do caso apresentado: franquia e veículos (elipses). Isso reforça a idéia de que, como o negócio não é conhecido, há uma tendência a buscar informações genéricas. 
Esta análise identificou uma diversidade bastante grande de informações, tanto gerais quanto específicas. Isso mostra que as informações externas são um recurso fundamental para os analistas de investimento, pois os diferentes tipos de informação são necessários para avaliar a empresa em si e a sua relação com o ambiente: setor, mercado e economia.

\section{Definição da Estratégia de Análise}

A definição das informações necessárias é importante, mas é apenas parte do que se pode chamar de estratégia de análise do investimento. A segunda parte da etapa de planejamento foi a definição de uma estratégia para avaliar a empresa. A tarefa solicitada foi descrever de que maneira o participante iria realizar a análise, considerando a oportunidade de investimento, citando as ações e a sequiência em que seriam realizadas.

Entre as diversas opções geradas, a Tabela 1 apresenta sete ações, citadas por todos os participantes do experimento. A seqüência foi identificada a partir do maior número de ocorrências em cada posição, ou seja, o momento em que cada ação aparece com maior freqüência durante o processo de análise.

\section{Tabela 1: Seqüência das Ações Identificadas como Estratégia de Análise}

\begin{tabular}{c|l|rc}
\hline Posição & \multicolumn{1}{|c|}{ Ação mais freqüente } & \multicolumn{2}{|c}{$\begin{array}{c}\text { Freqüiência (na } \\
\text { posição) }\end{array}$} \\
\hline $1^{\text {a }}$ & Obter informações sobre o negócio & 14 & $(51,8 \%)$ \\
$2^{\text {a }}$ & Obter informações na e sobre a empresa & 12 & $(44,4 \%)$ \\
$3^{\text {a }}$ & Obter informações no e sobre o mercado & 12 & $(44,4 \%)$ \\
$4^{\text {a }}$ & Fazer projeções e estimativas & 9 & $(33,3 \%)$ \\
$5^{\text {a }}$ & Avaliar a empresa & 10 & $(37,0 \%)$ \\
$6^{\text {a }}$ & Comparar informações & 13 & $(48,1 \%)$ \\
$7^{\text {a }}$ & Elaborar o relatório/fazer recomendações & 27 & $(100 \%)$ \\
\hline
\end{tabular}

As ações mais evidentes estão vinculadas à obtenção das informações identificadas anteriormente, mas surgiram outras ações relacionadas à avaliação dessas informações e à geração de novas informações. A seqüência, identificada a partir da freqüência, não pode ser considerada típica, pois há grande diversidade entre os analistas. Por exemplo, obter informações sobre o negócio é indicada como primeira ação do processo por catorze analistas. Entretanto os outros treze analistas indicaram essa ação em outro momento do processo. 
As outras ações identificadas dizem respeito ao tratamento dessas informações para interpretá-las (comparar as informações e avaliar a empresa) e produzir novas informações (fazer projeções e estimativas e elaborar o relatório/fazer recomendações). É interessante verificar que essa sequiência não é caracterizada tão claramente. Em alguns casos, a ação fazer projeções e estimativas aparece já na segunda posição, após obter informações na empresa e sobre a empresa. Em outros, aparece no final, precedendo a elaboração do relatório. Segundo os analistas, as projeções são fundamentais para uma decisão adequada sobre o investimento e podem ser realizadas em diversos momentos do processo.

A última ação, caracterizada como produto final do trabalho, é a elaboração de um relatório com a recomendação de investimento. O relatório (que pode ser apresentado de diversas formas) constitui-se no resultado gerado pelo analista para concretizar todo o encadeamento de ações realizado e registrar a sua contribuição como trabalhador de conhecimento.

\section{Análise da Empresa: Classificação e Avaliação das Informações Adicionais}

Nesta etapa do experimento, os analistas receberam uma lista com 22 informações sobre a empresa. Classificaram as informações na ordem de sua preferência, identificando como seria feita a análise. Depois, cada um recebeu as informações na ordem definida para avaliação.

\section{Classificação das Informações Adicionais}

A análise da ordem das informações adicionais definida pelos analistas é uma maneira de identificar diferentes abordagens para a avaliação do cenário. Foi utilizada a análise de agrupamentos (cluster), que revelou três grupos distintos de abordagens com relação à seqüência das informações: informações financeiras no início, no meio e no final do processo.

Quem iniciou a avaliação pelas informações financeiras estava interessado na mensuração do negócio, buscando até mesmo elementos para justificar ou não a avaliação. É uma abordagem pragmática, justificada por razões como: as informações financeiras determinam o retorno do investimento, mostram o desempenho da empresa, são a base para estimar as projeções de fluxo de caixa e definem o tamanho do negócio.

Os outros grupos, que optaram pelas informações financeiras no meio e no final do processo, consideraram que o tempo de existência da empresa não permitia a maturação do negócio e, portanto, a avaliação do desempenho estava 
prejudicada. É uma abordagem exploratória, justificada pela necessidade de conhecer a natureza do negócio.

Tanto as informações sobre o mercado e o negócio como da empresa não apresentaram uma sequiência definida, conforme foi descrito anteriormente. Mas há uma diferença sutil entre esses grupos. Os participantes que finalizaram a avaliação pelas informações financeiras dividiram o processo em duas partes, pois perceberam apenas dois tipos de informação. O grupo que optou pelas informações financeiras no meio do processo identificou três momentos distintos: características do negócio, informações financeiras e ações da empresa.

A partir dessas classificações, é possível verificar se há relação entre as etapas de planejamento e análise. Para isso, foi escolhida a ação fazer projeções e estimativas, que utiliza basicamente informações financeiras, pois ela aparece no início, no meio e no final da sequiência identificada no planejamento. A posição desta ação foi comparada com a abordagem de classificação das informações adicionais. A Figura 3 mostra que há coerência entre as etapas, pois a maioria dos participantes manteve a mesma posição para as projeções (estratégia) e para a avaliação das informações financeiras (análise).

Figura 3: Comparação entre as Etapas de Planejamento e Análise

\begin{tabular}{|c|c|c|c|}
\hline \multicolumn{2}{|l|}{ Planejamento } & \multicolumn{2}{|r|}{ Análise } \\
\hline Projeções no início & $\begin{array}{r}6 \\
11 \\
14 \\
17 \\
18 \\
19 \\
26 \\
\end{array}$ & \begin{tabular}{|r}
6 \\
11 \\
14 \\
17 \\
18 \\
19 \\
26 \\
\end{tabular} & $\begin{array}{c}\text { Informações } \\
\text { financeiras no } \\
\text { início }\end{array}$ \\
\hline & 1 & $\begin{array}{l}20 \\
25 \\
\end{array}$ & \\
\hline Projeções no meio & $\begin{array}{r}8 \\
9 \\
10 \\
12 \\
13 \\
21 \\
27 \\
\end{array}$ & \begin{tabular}{|r}
1 \\
5 \\
8 \\
12 \\
21 \\
27 \\
22 \\
\end{tabular} & $\begin{array}{c}\text { Informações } \\
\text { financeiras no } \\
\text { meio }\end{array}$ \\
\hline Projeções no final & $\begin{array}{r}2 \\
3 \\
4 \\
7 \\
15 \\
16 \\
20 \\
22 \\
23 \\
24 \\
25\end{array}$ & \begin{tabular}{|r}
2 \\
3 \\
4 \\
7 \\
15 \\
16 \\
23 \\
24 \\
9 \\
10 \\
13
\end{tabular} & $\begin{array}{c}\text { Informações } \\
\text { financeiras no } \\
\text { final }\end{array}$ \\
\hline
\end{tabular}




\section{Avaliação das Informações Adicionais}

Após receberem e avaliarem cada informação adicional, os analistas manifestavam suas opiniões sobre a oportunidade de investimento e comentavam os aspectos relevantes e a forma utilizada para interpretar a informação. Os comentários foram classificados em: associações de informações internas e externas, identificação das informações relevantes, condições para realizar o negócio e suposições para minimizar a falta de informações. Essa classificação de opiniões foi definida após o experimento, baseada no conteúdo dos comentários dos analistas.

\section{Associações de Informações Internas e Externas}

Associações entre informações do cenário e parâmetros dos analistas são formas de selecionar as informações importantes e descartar as consideradas pouco relevantes. É um procedimento subjetivo e, por isso, os julgamentos podem ser bastante diferentes.

As informações consideradas relevantes foram julgadas para determinar o valor da empresa. Esses julgamentos são subjetivos e genéricos, pois interpretam as informações de forma nominal (bom/razoável/ruim ou grande/médio/pequeno). Mesmo assim, são procedimentos importantes, pois comparam o significado das informações com parâmetros internos. É uma situação preliminar da elaboração de um quadro de referência que vai depois orientar a decisão.

Outra forma de associação, menos freqüente, agregou mais um componente: as projeções dos analistas. Além de selecionar e qualificar as informações, os parâmetros dos analistas também foram utilizados para definir um modelo ou técnica de avaliação. Ao fazer projeções, os analistas dependem de seus parâmetros para selecionar um conjunto restrito de informações, a forma como elas são tratadas e os critérios para atribuir um significado à avaliação.

Identificou-se um terceiro tipo de associação através de comparações entre as informações adicionais fornecidas. Com relação às informações financeiras, as comparações eram diretas. Como foram fornecidos quatro balanços patrimoniais e quatro demonstrações de resultados, os analistas verificaram o desempenho financeiro e manifestaram sua opinião se a situação da empresa melhorou ou piorou em relação ao período anterior. Outras comparações feitas foram: faturamento de cada loja (tempo de existência $X$ faturamento médio), faturamento e estrutura das lojas (faturamento $\mathrm{X}$ número de empregados/equipamentos), faturamento e resultado (faturamento $\mathrm{X}$ receitas e despesas) e prazos (aluguel das lojas $\mathrm{X}$ contrato de franquia).

Em todos os casos, os analistas descreveram e manifestaram a sua opinião em 
relação às comparações. Novamente, as opiniões revelam uma diversidade de julgamentos nominais que caracterizam aspectos positivos e negativos da empresa.

\section{Identificação das Informações Relevantes}

As informações avaliadas pelos analistas e identificadas como relevantes (acima de 5 ocorrências), foram: aluguel das lojas, contrato de franquia, despesas comerciais e administrativas, despesas e receitas operacionais, estratégia de crescimento, faturamento por loja, localização das lojas, margens operacionais, patrimônio líquido, potencial de mercado por bairro, previsão de retorno do investimento e serviços mais rentáveis.

A identificação de informações relevantes é particularmente importante nesta etapa do experimento. Além de representar uma forma de compreensão da informação recém-interpretada e evidenciar a sua relevância, é também um meio de recuperar informações avaliadas anteriormente para associá-las à atual. As comparações mostram que a identificação de informações relevantes está relacionada com outro tipo de ação: a associação entre informações do cenário.

Esses procedimentos novamente confirmam a característica de estruturar internamente as informações para melhorar o grau de compreensão do cenário e realizar a tarefa de avaliação.

\section{Condições para Realizar o Negócio}

As condições para avaliar o negócio são parâmetros definidos pelos analistas como sendo importantes para o trabalho de análise, pois são pré-requisitos para a avaliação.

No estudo, as condições definidas pelos analistas foram as seguintes:

. Qualidade da administração. Os administradores da empresa devem conhecer o negócio e mostrar que tomam decisões coerentes.

- Localização das lojas. A escolha das áreas mais adequadas para a localização das lojas é uma atribuição da administração do negócio e deve estar baseada em critérios técnicos.

Sócio minoritário e estratégico. Realizar apenas parte do investimento e não participar da administração do negócio.

- Retorno sobre o investimento. Entrar no negócio com uma taxa de retorno já definida (opções entre 12 e $25 \%$ ).

. Plano de crescimento. A empresa deve possuir um plano de crescimento do negócio, com estratégias e ações bem definidas. 


\section{Suposições para Minimizar a Falta de Informações}

As suposições são interpretadas como forma de preencher as lacunas percebidas pelos analistas, por entenderem que certas informações são insuficientes. No total, foram identificadas 58 suposições, das quais $48 \%$ ocorreu na avaliação das seis primeiras informações e $67 \%$ apareceu na avaliação das informações financeiras.

As informações não financeiras, que também geraram suposições, trataram dos seguintes assuntos: estratégia de posicionamento no mercado, segmentação de mercado por idade dos veículos, relação entre os negócios (administração da franquia e serviços de reparação) e estrutura societária. Além disso, algumas manifestações anteciparam informações que seriam fornecidas e avaliadas depois, confirmando ou não as suposições feitas.

Além de minimizar a falta de informações, o uso de suposições pode ser também interpretado como consequiência da característica do trabalho do analista. Como o seu objetivo é prever o comportamento futuro de uma empresa ou investimento, é necessário projetar um cenário. Como nem todas as informações estão disponíveis, é normal elaborar suposições para completar o quadro de referência. Pode-se afirmar que suposições são estimativas. Quando fundamentadas no conhecimento e na experiência do analista, podem ser entendidas como um nível cognitivo de criação de significado.

\section{Avaliação Final}

Nesta etapa, os analistas tomaram a decisão sobre o investimento e explicaram a forma como chegaram ao resultado da avaliação. Para chegar a esses resultados, os analistas consideraram as informações interpretadas durante o processo e incorporaram seus parâmetros.

O resultado final apresentou $14(51,9 \%)$ opções pelo investimento, $13(48,1 \%)$ não definições de proposta e nenhuma decisão de não investir. Embora as quantidades de tipos de propostas de participação não se tenham modificado muito, houve várias mudanças em relação à avaliação inicial, como mostra a Tabela 2.

\section{Tabela 2: Comparação dos Tipos de Proposta de Investimento - Inicial versus Final}

\begin{tabular}{l|rc|r|c|c}
\hline \multicolumn{1}{c|}{ Tipo de proposta de investimento } & \multicolumn{2}{c|}{ Avaliação Inicial } & Avaliação Final & Mudança \\
\hline Sem proposta (a) & 15 & $(55,6 \%)$ & $13(48,1 \%)$ & $4(\mathrm{~b} \rightarrow \mathrm{a})$ \\
Define uma proposta de investimento (b) & 12 & $(44,4 \%)$ & $14(51,9 \%)$ & $6(\mathrm{a} \rightarrow \mathrm{b})$ \\
Decide não realizar o investimento & 0 & $(0,00 \%)$ & $0 \quad(0,00 \%)$ & 0 \\
\hline
\end{tabular}


Os analistas que não definiram uma proposta argumentaram, como principal limitação, a falta de informações ou a necessidade de maior detalhamento. Foram apontadas como necessárias as seguintes informações: cenário macroeconômico, contrato de franquia mais detalhado, mais informações sobre o mercado (concorrentes, fornecedores e clientes), legislação do negócio de franquia e outras pesquisas de mercado. Comparando as informações necessárias identificadas nas avaliações inicial e final, não só o número de tipos de informação diminuiu, como também praticamente todas foram novas (exceto informações sobre o mercado). Provavelmente, após a avaliação, os analistas puderam especificar com maior exatidão as informações realmente necessárias para tomar uma decisão.

Outras razões que inibiram a definição de uma proposta foram: necessidade de aprofundar as projeções financeiras, necessidade de conversar com os administradores e conhecer as lojas, necessidade de discutir mudanças de estrutura e estratégia da empresa, pouco tempo de operação da empresa e resultados financeiros negativos.

Para esses casos, vale uma observação importante. Questionados sobre a apresentação de uma proposta de investimento, caso a avaliação pudesse ser aprofundada, todos os participantes responderam afirmativamente. Isso afasta uma possível confusão entre as opções de não definir uma proposta e a decisão de não investir e reforça a idéia de que o principal aspecto para a decisão foi a incerteza pelo investimento.

Já o grupo de analistas que apresentou uma proposta considerou diversos critérios para fundamentar a sua decisão. O item mais citado foi o estabelecimento de uma relação entre o potencial do negócio, a estratégia da empresa e os resultados financeiros (9 vezes ou 33\%), mas as posições foram diferentes. Todos, sem exceção, valorizaram o potencial do negócio. Entretanto as opiniões que consideraram os resultados financeiros mais importantes que a estratégia, tomaram decisões sobre como comprar a empresa, participar como gestor ou investir com uma margem de risco mínima. As propostas que julgaram os resultados negativos como menos importantes apresentaram uma relação investimento versus participação mais alta, valorizando mais os aspectos intangíveis e o potencial do negócio. Outro critério para definir a proposta foi estimar o valor do negócio, baseando-se nos resultados financeiros, no investimento inicial para abrir uma loja, em ativos intangíveis, ou em ambos.

Os participantes que optaram pelo investimento, mesmo considerando as informações financeiras como mais relevantes, atribuíram como principais razões o potencial do negócio e a definição estratégica da empresa. Isso aponta um tema que vem ganhando espaço no mercado financeiro e nas pesquisas da área: o valor dos ativos intangíveis (ver, por exemplo: Edvinsson \& Malone, 1998; Ernst\&Young, 1999). 
A análise desta etapa mostra que os parâmetros dos analistas são os elementos que têm maior influência na definição de um resultado, ou seja, esses parâmetros determinam quais os critérios que são utilizados para a avaliação e de que forma as informações são interpretadas.

\section{Contribuições para o Trabalho do Analista de Investimentos}

Este estudo revelou uma série de evidências que caracterizam padronização e diversidade no trabalho de análise de investimentos, resumidos no Quadro 2. A padronização é mais evidente no tipo de informações necessárias para a análise, no processo de trabalho e na seqüência de ações relacionadas ao uso da informação. A diversidade é identificada nas interpretações das informações, na aprendizagem gerada, no desempenho e nas decisões finais.

\section{Quadro 2: Padronização e Diversidade Identificadas na Pesquisa}

\begin{tabular}{|c|c|c|}
\hline Padronização/Diversidade & Resultados do estudo & Principal fator \\
\hline Padrões de informação & $\begin{array}{l}\text { - Empresa } \\
\text { - Negócio } \\
\text { - Franquia } \\
\text { - Setor } \\
\text { - Mercado } \\
\text { - Economia }\end{array}$ & Informações necessárias \\
\hline $\begin{array}{l}\text { Padrões de processo de } \\
\text { trabalho }\end{array}$ & $\begin{array}{l}\text { - Identificação de oportunidades de } \\
\text { investimento } \\
\text { - Conhecimento do analista x informações } \\
\text { externas aquisição de informações } \\
\text { - Técnicas de análise e projeções } \\
\text { - Decisões na forma de recomendações. }\end{array}$ & Mapeamento do processo \\
\hline $\begin{array}{l}\text { Padrões de processo de uso } \\
\text { da informação }\end{array}$ & $\begin{array}{l}\text { - Obter informações sobre o negócio } \\
\text { - Obter informações na e sobre a empresa } \\
\text { - Obter informações no e sobre o mercado } \\
\text { - Fazer projeções e estimativas } \\
\text { - Avaliar a empresa } \\
\text { - Comparar informações } \\
\text { - Elaborar o relatório/fazer recomendações }\end{array}$ & Estratégia de análise \\
\hline \multirow{4}{*}{ Diversidade } & - Interpretação das informações & $\begin{array}{l}\text { Capacidade cognitiva do } \\
\text { analista }\end{array}$ \\
\hline & $\begin{array}{l}\text { - Nível de aprendizagem e conhecimento } \\
\text { gerados }\end{array}$ & $\begin{array}{l}\text { Transformação das } \\
\text { informações durante o } \\
\text { processo }\end{array}$ \\
\hline & - Desempenho & Características do analista \\
\hline & - Decisão sobre investimento & $\begin{array}{l}\text { Interpretação das informações } \\
\text { e percepção de risco }\end{array}$ \\
\hline
\end{tabular}

O estudo mostrou que não há começo e final definidos para o processo de análise; as ações realizadas para o mesmo fim são diversificadas; as informações necessárias são diferentes para cada analista; a avaliação das informações pode gerar interpretações distintas e, finalmente, os resultados do trabalho, em termos de desempenho e decisão, são variados. 
Apesar de todas essas diferenças, o processo de trabalho obedece a algumas etapas: a busca e a identificação de oportunidades de investimento, a comparação entre o conhecimento do analista e a necessidade de informações externas, as maneiras de adquirir essas informações, as técnicas de análise e projeções para o futuro e as decisões na forma de recomendações.

Além disso, as abordagens nas etapas de planejamento e análise das informações adicionais apresentaram coerência; ou seja, o momento de realizar projeções (estratégia de planejamento) mostrou-se compatível com a avaliação das informações financeiras (análise das informações). Isso evidencia uma estruturação da atividade de análise de investimentos.

Por outro lado, não foram encontrados padrões em relação às propostas de investimento. Comportamentos e opiniões diferentes levaram a mudanças de proposta durante o processo, somente no final ou, ainda, a ausência de mudança. É importante lembrar que a avaliação do risco é individual, pois decorre da percepção do analista, levando-se em conta as informações que ele possuía no momento da decisão.

Este estudo verificou que ocorre uma transformação das informações ao longo do processo de trabalho. Essa transformação é causada pela seleção, interpretação e geração de informações. Durante a seleção, as informações consideradas não relevantes são descartadas. Aquelas que são aproveitadas precisam ser processadas. Mesmo que sejam geradas novas informações durante o processamento, há uma tendência de reduzir o volume para tornar a informação compreensível. Finalmente, a produção do relatório de análise indica uma recomendação de investimento. Podem ser apresentadas informações que explicam a decisão; mas o conteúdo realmente importante do relatório pode ser resumido em três informações simples: investir (ou não investir), quanto investir e quando investir. A transformação ocorre em termos de volume e conteúdo, além de o processo gerar novas informações.

Essa transformação é consistente com o que já é conhecido em áreas que estudam a informação; mas o seu resultado (o produto da transformação) revela uma tendência cada vez mais freqüente num ambiente onde o volume de informações disponíveis aumenta constantemente: a informação customizada. Como os investidores necessitam orientar suas decisões, buscam apoio em opiniões técnicas e informações organizadas indicadas pelos analistas, mesmo que possam discordar do que é apresentado. A sua interpretação resulta mais rápida, objetiva e apropriada. O relatório de análise deverá levar em conta o recebedor da informação, pois a recomendação de compra para um investidor pode significar venda para outro em função das diferentes percepções de risco de cada indivíduo.

O mapeamento do processo de análise de investimentos permitiu identificar 
que há necessidades distintas em termos de forma e conteúdo, busca e seleção diferentes em relação a fontes consultadas e a procedimentos para obtê-las e processamento e uso de informação variados quanto a recursos utilizados e interpretações resultantes do processo. Essa diversidade é resultado de o processo estar centrado na capacidade cognitiva do analista.

A característica da diversidade, associada à perspectiva de um crescimento constante de informação disponível no ambiente, exige que sejam criadas soluções flexíveis para gerenciar a informação. O problema da sobrecarga de informação não está no seu volume, mas no consumo de recursos. Assim, é sempre valioso que a forma e o conteúdo da informação sejam disponibilizados adequadamente em relação às necessidades e características de seu consumidor. Mas os recursos de informação é que devem apresentar soluções para a busca, seleção e processamento, liberando o trabalhador de conhecimento para dirigir a atenção para a sua atividade principal, de agregação de valor, que é a produção de conhecimento.

Aspectos organizacionais ligados ao uso da informação também devem ser considerados. O analista de investimentos é, pela natureza de sua atividade, um investigador de informações. Por outro lado, os ambientes organizacionais são os grandes provedores de informação. É fundamental estabelecer as condições adequadas de acesso à informação, como definição de políticas, reconhecimento da cultura, elaboração de normas e estruturação de tarefas. É importante lembrar o papel da instituição, da qual o analista faz parte, como um todo. Ao mesmo tempo que ela pode ser uma enorme fonte de informação, as reservas devem ser mantidas, prática conhecida como Chinese wall.

A ampliação de conhecimento como consequiência do processo de análise foi outro importante resultado da pesquisa. Isso reforça a abordagem de aprendizagem por experiência e tem implicações sobre os resultados do trabalho e o desenvolvimento profissional do analista. Em relação aos resultados do trabalho, o domínio do processo de análise, da gerência da informação e do conhecimento da empresa ou setor avaliado implica melhor desempenho. Sobre o desenvolvimento profissional, a utilização de instrumentos que reproduzam a realidade - como simulações, casos e cenários - e a análise dos resultados produzidos a partir das decisões dos participantes é um dos recursos didáticos adequados para profissionais que trabalham com informação e possuem atividades de natureza analítica.

Finalmente, os resultados também indicam contribuições para a área de tecnologia da informação, que tem papel importante para ocupar no ambiente de análise de investimentos. O desenvolvimento de recursos que auxiliem a realização de tarefas baseadas em conhecimento, sistemas que estimulem e facilitem a interação de especialistas e a criação de bases de documentação técnica e de processos para registrar e compartilhar conhecimento são algumas das aplicações possíveis nessa área. 


\section{Conclusões}

Já foi ressaltado que a capacidade do analista em gerenciar informações e produzir resultados lhe confere o papel de processador de informações e gerador de conhecimento. $\mathrm{O}$ caráter cíclico do processo exige do analista competência para prospectar e monitorar o mercado.

Na qualificação dos profissionais da área, com atividades voltadas ao mercado de capitais, à avaliação de empresas e a projetos de investimento, o foco deve ser o desenvolvimento da capacidade do analista para trabalhar com informações, reforçando o seu papel de processador de informações e gerador de conhecimento. Os padrões evidenciados, referentes às informações necessárias no mapeamento do processo de trabalho e à estratégia de análise, constituem-se em elementos valiosos para a estruturação de programas de qualificação.

Por outro lado, a diversidade associada ao tipo e ao processamento das informações e a constatação da importância das características individuais dos analistas implicam ações de reconhecimento e estímulo ao desempenho, além do desenvolvimento de sistemas de informação e de apoio à decisão adaptativos e que favoreçam a proatividade dos profissionais da área. Por isso, tanto a padronização quanto a diversidade identificadas neste estudo têm atributos que devem ser aproveitados por profissionais e empresas que realizam análise de investimentos.

Entretanto cabe ressaltar que os resultados aqui apresentados não podem ser generalizados, principalmente pela especificidade dos analistas que participaram da pesquisa. Por outro lado, justamente pelo nível dos analistas, esses resultados contribuem para estabelecer um marco no relacionamento e na estrutura de avaliação de empresas, conforme proposto no trabalho.

Além disso, embora o experimento tenha apresentado limitações por não reproduzir integralmente o processo de análise (por exemplo, os analistas não conversaram com os administradores da empresa, não visitaram as lojas, não fizeram projeções financeiras), isso não invalida a investigação. Como foi mencionado anteriormente, a utilização do cenário possibilitou captar a dinâmica do processo de aquisição, interpretação e uso da informação para produzir resultados. Portanto, essa forma de investigação contribuiu para melhor compreensão da natureza da análise de investimentos como atividade de trabalho de conhecimento.

Artigo recebido em 10.08.2004. Aprovado em 01.03.2005. 


\section{Agradecimentos}

Os autores agradecem ao CNPq o auxílio recebido para esta pesquisa.

\section{NotAs}

${ }^{1}$ Embora a atividade do analista seja essencialmente única - determinar o valor correto para um ativo objeto de investimento - são consideradas as suas diferentes aplicações: operações de compra e venda de títulos e valores mobiliários, administração de carteiras, administração de fundos mútuos de investimento, underwriting (lançamento público de ações), subscrição de ações, fusões e aquisições etc. (Rudge \& Cavalcante, 1993).

${ }^{2}$ Foi perguntado explicitamente a cada participante, no início do experimento, se ele conhecia a empresa e o setor de atividade. Todos responderam negativamente.

${ }^{3}$ Especialistas são definidos por indicadores como tempo de atividade, formação acadêmica e profissional, desempenho (qualidade técnica e resultados obtidos) e o reconhecimento de seus pares, superiores à média na sua atividade (Agnew et al., 1994; Ericsson \& Smith, 1991).

\section{Referências Bibliográficas}

Agnew, N. M.,

Ford, K. M., \&

Hayes, P. J. (1994, January).

Expertise in Context: personally constructed, socially selected, and reality-relevant? International Journal of Expert Systems, 7(1), 65-88.

Berkowitz, S.,

Finnery, L., \&

Logue, D. (1988).

The investment performance of corporate pension plans. New York: Quorom Books.

Bernard, V., \&

Thomas, J. (1990, December).

Evidence that stock prices do not fully reflect the implications of current earnings for future earnings. Journal of Accounting and Economics, 13(4), 305-340.
Boff, L. H., \&

Hoppen, N. (2001).

Desenvolvimento e Validação de Instrumentos de Pesquisa para a Área de Trabalho de Conhecimento. Anais do Encontro Nacional dos Programas de Pós-Graduação em Administração, Campinas, SP., 25.

Brinson, G., Hood, R., \&

Beebower, G. (1986, July/August).

Determinants of portfolio performance. The Financial Analysts Journal, 42(4), 39-44.

Choo, C. W., \& Auster, E. (1993).

Environmental scanning: acquisition and use of information by managers. In M. E. Williams (Ed.). Annual Review of Information Science and Technology (Vol. 28, pp. 279-314). Medford, NJ: Learned Information, Inc. 
Dervin, B. (1992).

From the mind's eye of the "user": the sensemaking qualitative-quantitative methodology. In J. D. Glazier, \& R. R. Powell (Eds.). Qualitative Research in Information Management. Englewood, CO: Libraries Unlimited.

Edvinsson, L., \&

Malone, M. S. (1998).

Capital intelectual. São Paulo: Makron.

Ericsson, K. A., \&

Smith, J. (1991).

Prospects and limits of the empirical study of expertise: an introduction. In K. A. Ericsson, \& J. Smith (Eds.). Toward a general theory of expertise: prospects and limits (pp. 01-38). New York: Cambridge University Press.

Ernst\&Young (1999).

Measures that matter. Recuperado em 14 fevereiro, 2001, de www.businessinnovation.ey.com/ research/perfor/measures.pdf

Fama, E. F. (1970, May).

Efficient capital markets: a review of theory and empirical work. Journal of Finance, 25(2), 383-417.

Finnerty, J. E. (1976, September).

Insiders and market efficiency. Journal of Finance, 31(4), 1141-1148.

Newell, A., \&

Simon, H. A. (1972).

Human Problem Solving. Englewood Cliffs: Prentice-Hall, 1972.
Rudge, L. F., \&

Cavalcante, F. (1993).

Mercado de Capitais. Belo Horizonte:

Comissão Nacional de Bolsas de

Valores.

Seyhun, H. N. (1986, June).

Insiders' profits costs of trading and market efficiency. Journal of Financial Economics, 16(2), 189-213.

Staël Von Holstein, C. A. S. (1972, August). Probabilistic forecasting: an experiment related to the stock market. Organizational Behavior and Human Decision Processes, 8(1), 139158.

Sundali, J. A., \&

Atkins, A. B. (1994, August).

Expertise in investment analysis: fact or fiction. Organizational Behavior and Human Decision Processes, 59(2), 223-241.

Taylor, R. S. (1986).

Value-added processes in information systems. Norwood: Ablex Publishing.

Yates, J. F.,

McDaniel, L. S., \&

Brown, E. S. (1991, June).

Probabilistic forecasts of stock prices and earnings: the hazards of nascent expertise. Organizational Behavior and Human Decision Processes, 49(1), 60-79. 